\title{
An instrumental cigarette smoke monitor designed for the direct measurement of smoke particulate matter generated in human smoking studies
}

\author{
ROGER A. JENKINS and THOMAS M. GAYLE \\ Oak Ridge National Laboratory, Oak Ridge, Tennessee
}

\begin{abstract}
An instrumental cigarette smoke monitor (CSM) system designed for human smoking studies has been developed and validated using a smoking machine as a human surrogate. The cigarette holder contains both smoke-mixing and flow-measurement orifices and a smoke-concentration sensor. Smoke flow through the holder and smoke concentration in the holder are determined simultaneously. The two signals are multiplied electronically and the product signal integrated. The integrated response is directly proportional to the amount of particulate matter collected immediately downstream of the holder, regardless of cigarette type or the particular way in which the cigarette is smoked. The CSM is sufficiently sensitive to quantitatively determine the amount of smoke TPM generated from cigarettes in the 1-mg Federal Trade Commission tar-delivery category.
\end{abstract}

There is increasing evidence (Benowitz, Hall, Herning, Jacob, Jones, \& Osman, 1983; Creighton \& Lewis, 1978; Gust \& Pickens, 1982; Herning, Jones, Bachman, \& Mines, 1981; Herning, Jones, Benowitz, \& Mines, 1983; Robinson, Young, Rickert, Fey, \& Kozlowski, 1983; Russell, Jarvis, Iyer, \& Feyerabend, 1980; Stepney, 1980; Sutton, Russell, Iyer, Feyerabend, \& Saloogee, 1982) that the amount of smoke that smokers receive from their cigarettes is at least as much a function of the manner in which they smoke (puff volume, shape, frequency, ventilation-hole obstruction) as it is a function of the individual brand that they consume. In an attempt to quantify the amount of smoke generated by an individual smoker for inhalation, smoking behavioralists have used a number of devices to characterize smoking performance (Creighton, Noble, \& Whewell,

This project was sponsored by the National Cancer Institute Department of Health and Human Services, under Interagency A rreement Nos. DOE 40-485-74 NCI Y01-CP-60206 and DOE: 40-485-74 NCI Y01-CP-30508 under Union Carbide Corporation Contract W-7405-eng-26 with the U.S. Department of linergy. The contents of this publication do not necessarily reflect the views or policies of the Department of Health and $\mathrm{Hu}$ man Services, and the mention of trade names, commercial products, and organizations does not imply endorsement by the U.S. Covernment. This work was presented in part at the 36 th Tobacco Chemists' Research Conference, Raleigh, NC. October 24-27, 1982. R.A. Jenkins is with the Analy tical Chemistry Division. and T. M. (iayle is with the Instrumentation and Controls Division. both at the Oak Ridge National Laboratory, Oatk Ridger, TN 378.30 .
1978; Griffith \& Dugan, 1983; Gust, Pickens, \& Pechacek, 1983; Little, 1977). Most of these devices measure puffing flow through an orifice in a small cigarette holder. The resulting puff profile and volume are used to describe the individual's smoking performance, topography, or behavior. Recently, such a device has become commercially available (Filtrona Instruments and Automation, Ltd., Richmond, VI). Although these devices represent a marked advance in understanding smoking behavior, the use of puff volume, shape, frequency, etc., to describe the amount of smoke generated during a smoking experience suffers from some important limitations. The amounts of constituents [total particulate matter (TPM), carbon monoxide (CO), nicotine, etc.] generated from a puff of specified volume for a particular cigarette type or brand depends on both the shape of the puff (Creighton \& Lewis, 1978; Seehofer \& Wennberg, 1971) and its position in the overall puffing sequence (DeBardeleben, Claflin, \& Gannon, 1978). In other words, a specific size and shape puff will produce more TPM, CO, etc., when taken near the butt end of the cigarette than when taken shortly after the cigarette has begun to be smoked. Thus, to determine the amounts of smoke constituents generated using smoking-topography data, a puff-duplicating smoking machine would have to be used. Such a device, essentially a slave smoking machine driven by a paper-tape record of the human smoking experience, has been reported (Creighton et al., 1978). However, even if a second sample of the particular brand in question is machine smoked in a manner 
identical to that of the human smoker, cigarette-tocigarette variability may render the results obtained nonrepresentative of the smoke delivery that was obtained by the smoker.

To our knowledge, there have been no reports of direct measurements of any smoke constituent generated by smokers. Here, we report on the design and validation of a system that provides a direct readout of the TPM generated from any cigarette smoked. The measurement is based on the real-time determination of smokeparticle concentration and flow through a small cigarette holder. The device is sufficiently sensitive to accurately measure smoke outputs from cigarettes in the 1-mg tar Federal Trade Commission (FTC) classification (FTC, 1983).

\section{METHOD}

\section{System}

The experimental assembly, depicted schematically in Figure 1, consists of three major components: the cigarette holder, the flow-measurement system, and the smoke-concentration monitor/multiplier/integrator electronics package. The cigarette holder (detailed drawings are available from the authors upon request) has three parts: a detachable cylinder for holding the cigarette, the main body of the holder, and a small tube (not shown) designed to interface to either a small disposable mouthpiece for human smoking or a standard Cambridge filter assembly (Wartman, Cogbill, \& Harlow, 1959) for evaluation studies. Inside the body of the holder, there is a 2.4-mm i.d. smokemixing orifice, a $2.0-\mathrm{mm}$ i.d. orifice across which pressure drop is sensed for flow measurement, and an optical smoke-concentration sensor (TRW/Optron Model OPB 710). On each side of the flow-measurement orifice is a tap for small-bore (i.d.) flexible tubing. Total dead volume within the cigarette holder is $1.6 \mathrm{ml}$.

The flow-measurement system is an ADL Smoke Dosimeter (Arthur D. Little, Inc., Cambridge, MA), a smoking-topography device designed to measure the pressure drop across the orifice $\left(F=k \Delta p^{0.45-4 t .55}\right.$, where $F=$ flow rate, $p=$ pressure drop, and $\mathrm{k}$ is a constant) and to output a signal that is directly proportional to the flow rate. This is accomplished by analog linearizing circuitry. The dosimeter is also capable of integrating the flow to provide puff-volume information. The linearized flow signal is attenuated by a 10-turn precision potentiometer, such that the

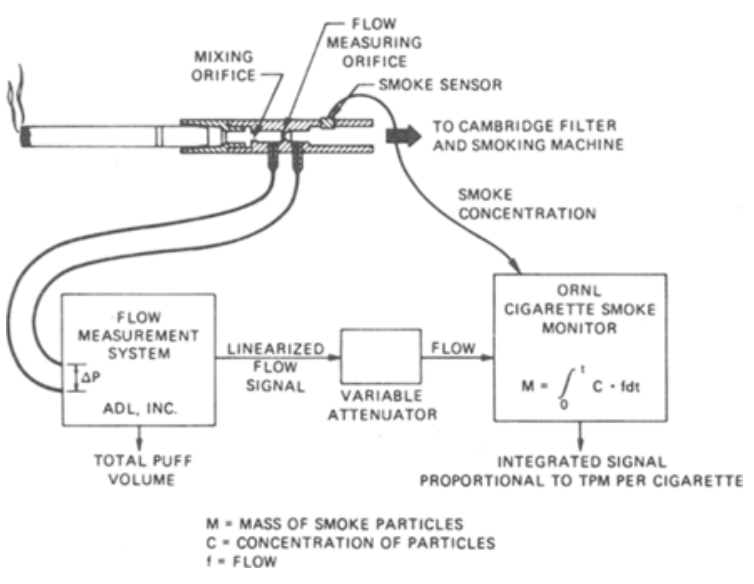

Figure 1. Schematic diagram of cigarette smoke monitor (CSM). input-signal level is appropriate for the cigarette smoke monitor (CSM).

The CSM contains the smoke-sensor support electronics, an analog multiplication circuit, and an integrator circuit, and has been described in detail elsewhere (Jenkins \& Cayle, 1980). The output, in integrator counts, is proportional to the integrated product of the smoke and flow signals.

\section{Evaluation Procedure}

Experimental cigarettes used in this study were obtained from either the National Cancer Institute (codes A-1, A-2, or A-3) or the University of Kentucky Tobacco and Health Research Institute (code 2R1). Commercial cigarettes were obtained from a local tobacco wholesaler. Prior to being smoked, all cigarettes were maintained under standard conditions (Pillsbury, Bright, O'Connor, \& Irish, 1969) of $75 \pm 2^{\circ} \mathrm{F}$, and $60 \pm 2 \%$ relative humidity for at least $48 \mathrm{~h}$. In order to evaluate the CSM, a standard Cambridge filter assembly (Wartman et al., 1959) was attached to the downstream end of the cigarette holder. This was in turn attached to the inlet port of a single port analytical smoking machine (Horton \& Guerin, 1974). The machine is capable of producing approximately sinusoidally shaped puffs of volumes ranging from 10 to $100 \mathrm{ml}$. Cigarettes were usually-but not always-smoked to the whole puff nearest the standard butt length (Pillsbury et al., 1969) of $23 \mathrm{~mm}$ for nonfiltered varieties or to within $3 \mathrm{~mm}$ of the filter overwrap for filtered cigarettes. The weight increase of the Cambridge filter assembly (Ogg, 1964) was taken to be the TPM delivery per cigarette. Occasionally, a manually operated syringe was used to generate unconventionally shaped puffs.

\section{RESULTS AND DISCUSSION}

\section{Principle of Operation}

The design and operation of the CSM is based on the equation

$$
M=\int_{0}^{t} C \cdot f d t
$$

where $\mathbf{M}=$ mass of smoke particles passing through the cigarette holder (in milligrams), $\mathrm{C}=$ smoke concentration at the smoke sensor location (in milligrams/liter), and $\mathrm{f}=$ flow rate through the holder (in liters/minute).

Instrumentally, the smoke sensor, a light-emittingdiode/phototransistor combination, responds to emitted infrared "light" that is back-scattered by the smoke droplets. The attenuated flow signal is continuously multiplied by the smoke-concentration signal. The product signal is passed to a voltage-to-frequency converter and then to a frequency counter for integration. The sequence of events is depicted on the oscilloscope trace in Figure 2. Prior to the initiation of the puff, the smoke concentration inside the holder is high, due to particulate matter that remains from the previous puff. Of course, flow rate is zero, so the resulting product signal is zero. At the beginning of the puff, smoke of relatively low particle concentration rushes into the holder, and, although the flow is increasing, the product is small. The product signal reaches its peak when both smoke concentration and flow are near their respective maxima. The product signal decreases to zero with that of the flow, while that of the smoke concentration 
ORNL-DWG 82-18012

CIGARETTE SMOKE MONITOR RESPONSE

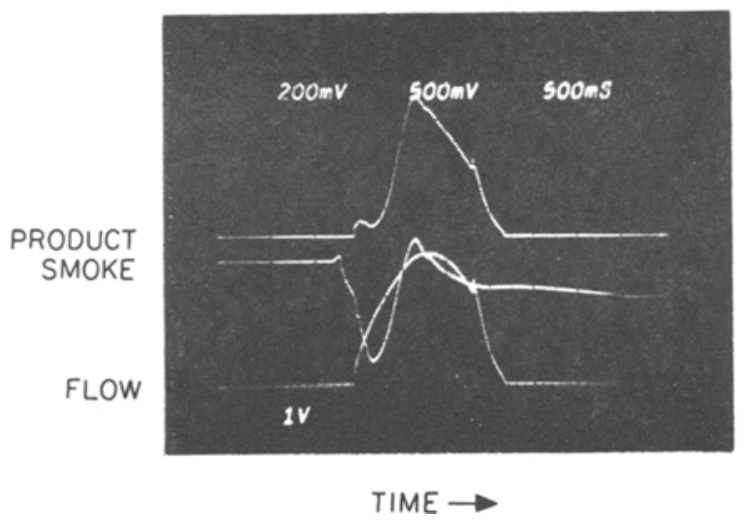

Figure 2. Oscilloscope trace of CSM response: smoke concentration, flow, and smoke-flow product signals.

remains relatively high. The area under the product peak is taken as the amount of smoke passing the sensor during the puff.

\section{Design Considerations}

The efficiency with which infrared radiation is back. scattered by a collection of particles is a function of the number of particles and their diameter (Green \& Lane, 1964). For a condensation aerosol such as cigarette smoke, the response of a back-scatter detector is fortuitously proportional to the particle mass per unit volume (i.e., mass concentration). In fact, studies with this smoke-concentration system have demonstrated linearity of response to particle concentrations from $100 \mathrm{microg} / \mathrm{L}$ to $100 \mathrm{mg} / \mathrm{L}$ (Jenkins \& Gayle, 1980). However, the response of the sensor also depends on the distance from the sensor to the smoke cloud, an especially critical factor in this application. Many modern commercial cigarettes possess ventilated filters. The smoke streaming from the filter-tip end often exhibits a radially assymmetric pattern, the shape of which depends on the ventilation characteristics of the particular cigarette in question. Thus, the response of the smoke concentration sensor could depend on the orientation of the individual cigarette in the holder, as illustrated in Figure 3. Early studies in our laboratory with a prototype holder had indicated a variety of response levels to comparable levels of TPM in the case of more highly ventilated cigarettes. By placing clear tubing between the cigarette and the holder, the smoke was observed to stream from the filter, and not to fill the entire volume of the tube. This streaming was judged to be responsible for the response differentials. Mixing the smoke seemed to alleviate the problem. By trial and error, the most effective system for mixing the smoke without adding considerable pressure drop to the holder was determined to be two orifices in sequence upstream of the smokeconcentration sensor. This concept was incorporated into the final holder design by placing the sensor downstream of both the flow-measurement and mixing orifices. After the smoke had passed through the two orifices, no inhomogeneity in the smoke cloud could be detected on oscillographic traces of sensor response alone.

The turbulence caused by the mixing orifice disturbs the flow regime through the flow-measurement orifice somewhat. This gives rise to a small inaccuracy in the indicated flow through the cigarette holder, relative to the actual flow. The data portrayed graphically in Figure 4 indicate that the relative error was usually not greater than $7 \%$ over the range of flows likely to be encountered under normal human smoking conditions. Placement of the measurement orifice upstream of the mixing orifice would have served to decrease this error somewhat, but would have increased the dead volume and time lag between the flow-rate and smoke-concentration measurement points $(0.37 \mathrm{ml}$ and $21 \mathrm{msec}$ at $17.5 \mathrm{ml} / \mathrm{sec}$, respectively, in the current configuration).

The presence of two orifices in the holder resulted in only a small additional pressure drop beyond that of a conventional cigarette. At the standard flow of $17.5 \mathrm{ml} /$ $\mathrm{sec}$, total pressure drop was $3.5 \mathrm{~mm}$ water. Since this was in addition to typical pressure drops of $70-150 \mathrm{~mm}$ of water (at $17.5 \mathrm{ml} / \mathrm{sec}$ ) for most commercial cigarettes, the added flow resistance was judged to be unimportant to the human smoking experience.

\section{Evaluation Studies}

The sensor response as a function of collected TPM for several types of cigarettes smoked under standard conditions is portrayed in Figure 5. The data indicates

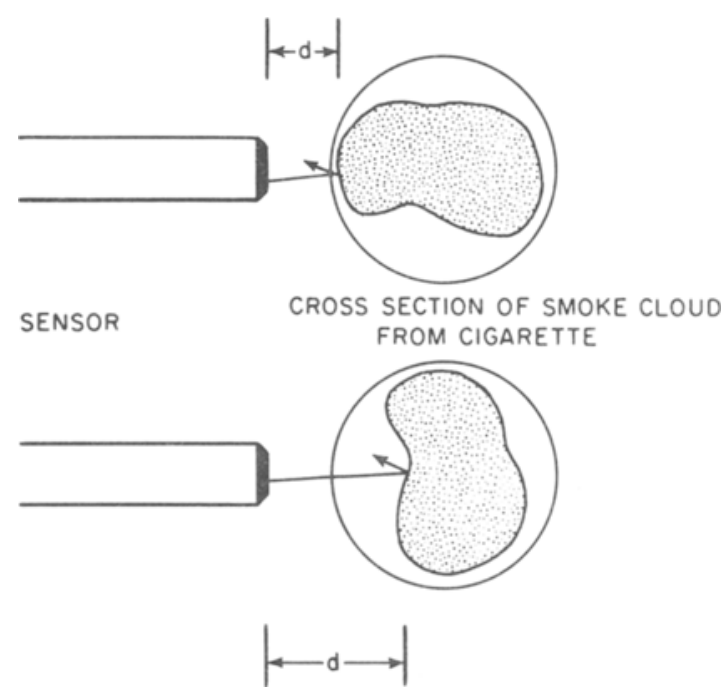

Figure 3. Schematic diagram: Smoke sensor response is a function of the distance to the smoke cloud. 


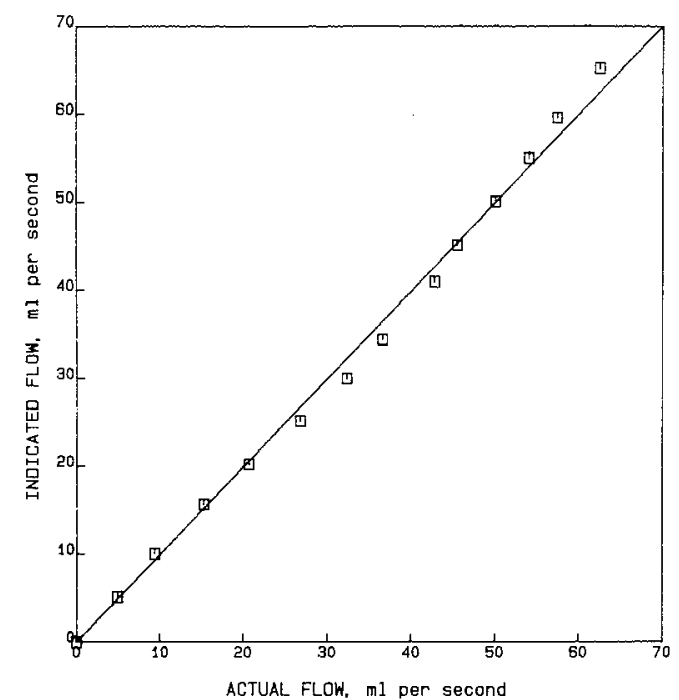

Figure 4. Comparison of actual flow through cigarette holder with that determined by CSM.

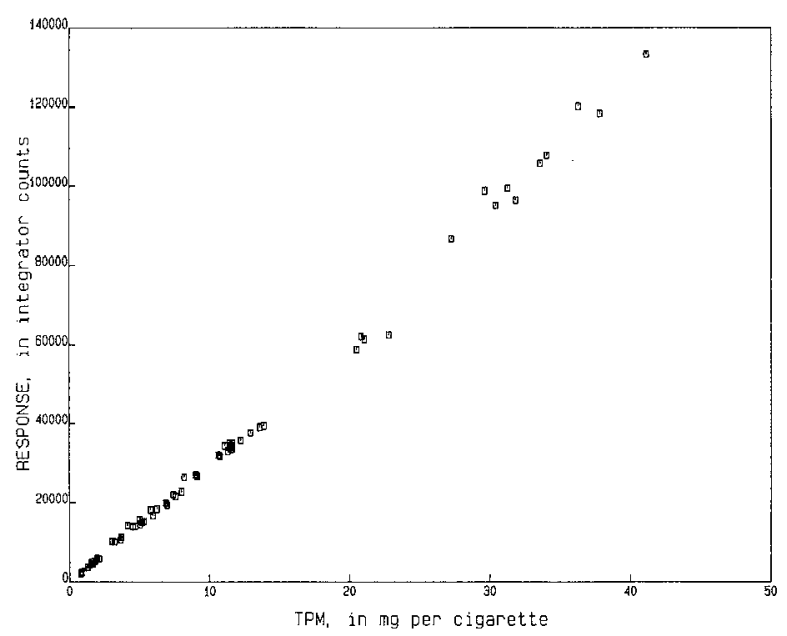

Figure 5. Response of CSM as a function of TPM delivery of cigarettes smoked under standard puffing conditions.

that the response is relatively linear, with a slight upward deviation at higher TPM deliveries. Average response factors (in counts per milligram TPM collected) for several brands with a wide range of smoke deliveries are tabulated in Table 1 . The average response factor for all brands was about 2,990 counts $/ \mathrm{mg}$, with a relative standard deviation of $4.4 \%$. The data indicate that the system sensitivity is independent of the amount of TPM delivered by the cigarette.

In order to examine the effect of different smoking parameters on system response, cigarettes were smoked at puff volumes ranging between 17 and $75 \mathrm{ml}$ and durations varying from 1.0 to $3.0 \mathrm{sec}$, the extremes of the ranges likely to be encountered with human smoking (Armitage, 1978). Data obtained from an ultralow-tar variety ( $1 \mathrm{mg}$ of tar by FTC test) are portrayed in Fig. ure 6, and data from several individual brands are portrayed in Figure 7. Puffing the cigarettes manually to produce nonsinusoidal puff shapes resulted in no differences in response patterns. All of the data indicated that, over the delivery ranges examined, response rate was essentially linear with TPM delivery. Careful, detailed examination of the data obtained at the lowest puff volumes $(17 \mathrm{ml})$ indicated that the system was somewhat more sensitive (15\%) to smoke generated under these conditions. Measurement of the temperature of the smoke passing the sensor indicated that, although the sensor responded to infrared radiation, differences in the smoke temperature had no effect on sensor response. The increased response rate at low puff volumes was presumed to be due to some change in the back-scattering properties of smoke generated under these conditions.

Limited experiments with extremely low-delivery cigarettes $(0.1 \mathrm{mg}$ of tar under FTC method) indicated that the system responded to smoke-particle deliveries from these cigarettes. However, the quantitative evaluation of response was virtually impossible, despite attempts at collecting the smoke from several cigarettes (up to 10) on a single filter pad and averaging the results. Two conditions probably contribute to irreproducible response. First, smoke-particle concentrations of $1 \mathrm{microg} / \mathrm{ml}$ (e.g., $0.2 \mathrm{mg}$ dispersed into seven $35-\mathrm{ml}$ puffs) are considerably below the normal working range of the sensor. In addition, the short optical path length required by the cigarette holder configuration tends to further diminish the sensitivity. Second, errors in weighing at these levels of collected material can be considerable. Accurate determination of particles in cigarette smoke, even with prepuffing of the filter pads, is so fraught with difficulties that the FTC refuses to report tar deliveries below $0.5 \mathrm{mg}$ per cigarette (FTC, 1983).

Table 1

Cigarette Smoke Monitor Response as a Function of TPM Delivery

\begin{tabular}{crrrr}
\hline & & \multicolumn{3}{c}{ Response** } \\
\cline { 3 - 5 } Cigarette & & Mean & SD & Relative SD \\
\hline Brand A & 1.2 & 2822 & 89 & 3.2 \\
Brand B & 3.8 & 3199 & 209 & 6.5 \\
Brand C & 5.3 & 2916 & 112 & 3.8 \\
Brand D & 5.5 & 2976 & 157 & 5.3 \\
Brand E & 7.8 & 2891 & 58 & 2.0 \\
Brand F & 10.4 & 3020 & 130 & 4.3 \\
Brand G & 12.9 & 2881 & 33 & 1.1 \\
Brand H & 21.3 & 2872 & 101 & 3.5 \\
A-1 & 31.5 & 3169 & 110 & 3.5 \\
A-2 & 11.1 & 2989 & 71 & 2.4 \\
A-3 & 1.8 & 2979 & 211 & 7.1 \\
2R1 & 36.7 & 3204 & 71 & 2.2 \\
Mean Response & & 2993 & 132 & 4.4 \\
\hline
\end{tabular}

Note-TPM means given in milligrams; response means given in counts per milligram; and relative $S D$ given in percent. ${ }^{*} \mathrm{Ob}$ tained at 35-ml puff, 2.0-sec duration, 1 puff $/ \mathrm{min} . \quad$ *Reported to the nearest single count, although the number of significant digits was only 2 or 3. 


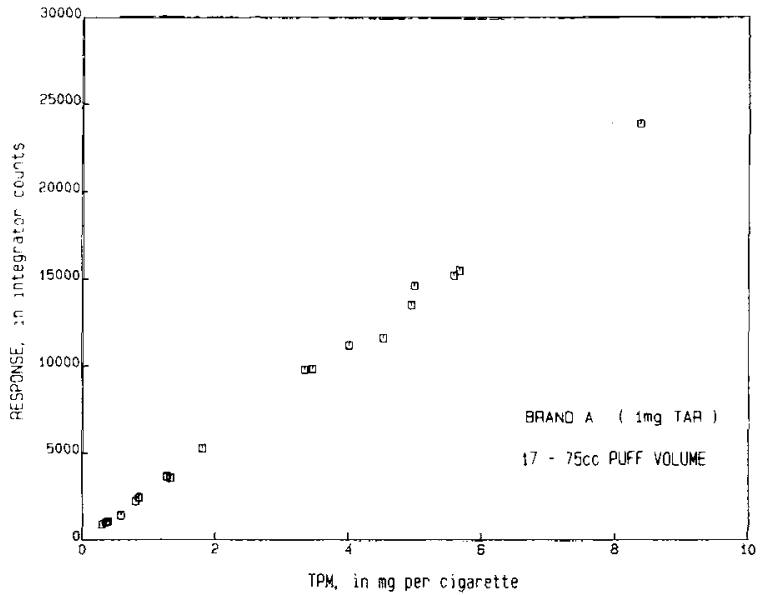

Figure 6. CSM response as a function of TPM delivery of ultralow-tar cigarette smoked under both standard and nonstandard puffing conditions.

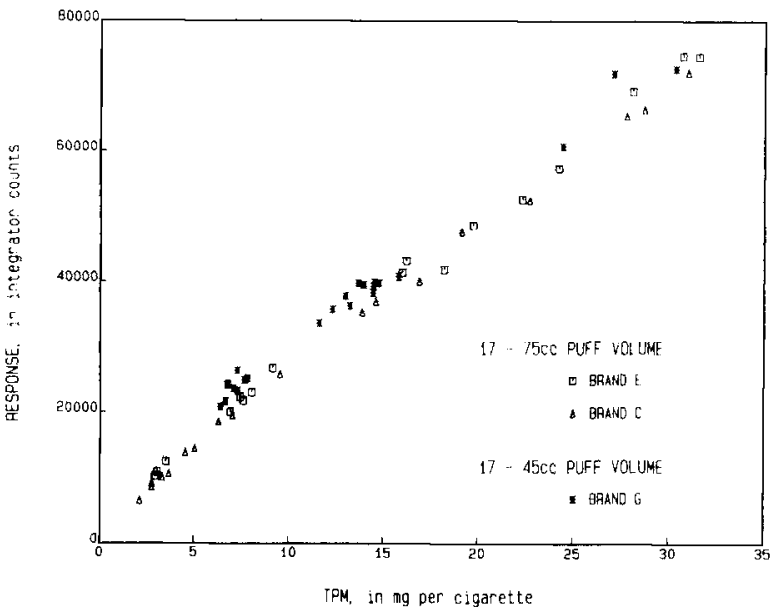

Figure 7. CSM response as a function of TPM delivery for three cigarette brands smoked under more humanly relevant puffing parameters.

\section{REFERENCES}

Armitage, A. K. (1978). The role of nicotine in the smoking habit. In R. E. Thornton (Ed.), Smoking behaviour: Physiological and psychological influences. Edinburgh, Scotland: Churchill Livingstone.

Benowitz, N. L., Hall, S. M., Herning, R. I., Jacob, P., III, Jones, R. T., \& Osman, A. L. (1983). Smokers of low yield cigarettes do not consume less nicotine. New England Journal of Medicine, 309, 139-142.

Creighton, D. E., \& Lewis, P. H. (1978). The effect of smoking pattern on smoke deliveries. In R. E. Thornton (Ed.), Smoking behaviour: Physiological and psychological influences. Edinburgh, Scotland: Churchill Livingstone.

Creighton, D. E., Noble, M. J., \& Whewell, R. T. (1978). Instruments to measure, record and duplicate human smoking patterns. In R. E. Thornton (Ed.), Smoking behaviour: Physiological and psychological influences. Edinburgh, Scotland: Churchill Livingstone.
DeBardeleben, M. Z., Claflin, W. E., \& Gannon, W. F. (1978). Role of cigarette physical characteristics on smoke composition. Recent Advances in Tobacco Science, 4, 85-111.

Federal Trade Commission. (1983). "Tar," nicotine and carbon monoxide of the smoke of 208 varieties of domestic cigarettes. Washington, DC

Green, H. L., \& Lane, W. R. (1964). Particulate clouds: Dusts, smokes, and mists. Princeton, NJ: Van Nostrand.

Griffith, R. B., \& Dugan, R. J. (October 1983). A microcomputer program for characterizing smoking behavior. Paper presented at the Tobacco Chemists' Research Conference, Washington, DC.

Gust, S. W., \& Pickens, R. W. (1982). Does cigarette nicotine yield affect puff volume? Clinical Pharmacology and Therapeutics, 32, 418-422.

Gust, S. W., Pickens, R. W., \& Pechacek, T. F. (1983). Recording puff volume in smoking. Behavior Research Methods \& Instrumentation, 15, 341-343.

Herning, R. I., Jones, R. T., Bachman, J., \& Mines, A. H. (1981). Puff volume increases when low nicotine cigarettes are smoked. British Medical Journal, 283, 187-189.

Herning, R. I., Jones, R. T., Benowitz, N. L., \& Mines, A. H. (1983). How a cigarette is smoked determines blood nicotine levels. Clinical Pharmacology and Therapeutics, 33, 84-90.

Horton, A. D., \& Guerin, M. R. (1974). Gas-solid chromatographic determination of carbon monoxide and carbon dioxide in cigarette smoke. Journal of the Association of Official Analytical Chemists, 57, 1-7.

JENKINS, R. A. \& GAYIF, T. M. (1980). An instrumental inhaled smoke dosimeter for the quantitative characterization of aerosol exposures. Pulmonary Toxicology of Respirable Particles: Proceedings of the Nineteenth Annual Hanford Life Sciences Symposium at Richland, Washington, October 22-24, 1979 (pp. 66-86). (NTIS No. CONF-791002)

Little, Arthur D., Inc. (1977). Smoke dosimeter, developed for the National Cancer Institute, National Institutes of Health (Contract No. 1-CP-55666). Washington, DC: Author.

OGG, C. L. (1964). Determination of particulate matter and alkaloids (as nicotine) in cigarette smoke. Journal of the Association of Official Agricultural Chemists, 47, 358-362.

Pillsbury, H. C., Bright, C. C., O'Connor, K. J., and Irish, F. W. (1969). Tar and nicotine in cigarette smoke. Journal of the Association of Official Analytical Chemists, 52, 458-462.

Robinson, J. C., Young, J. C., Rickert, W. S., Fey, G., \& Koztowsk1, L. T. (1983). A comparative study of the amount of smoke absorbed from low yield ("less hazardous") cigarettes, Part 2: Invasive measures. British Journal of Addiction, 78, 79-87.

Russell, M. A. H., Jarvis, M., Iyer, R., Feyerabend, C. (1980). Relation of nicotine yield of cigarettes to blood nicotine concentration in smokers. British Medical Journal, 280, 972-976.

Seehofer, F., \& Wennberg, D. (1971). Einfluss verschiedener Zug volumenprofile auf Ausbeute und Zusammensetzung des Rauches beim maschinellen Abrauchen von Cigaretten. Beitrage zur Tabakforschung, 6, 7-11.

STEPNEY, R. (1980). Consumption of cigarettes of reduced tar and nicotine delivery. British Journal of Addiction, 75, 81-88.

Sutton, S. R., Russell, M. A. H., Iyer, R., Feyerabend, C., \& Salooge E, Y. (1982). Relationship between cigarette yields, puffing patterns, and smoke intake: Evidence for tar compensation. British Medical Journal, 258, 600-603.

Wartman, W. B., JR., Cogbill, E. C., \& Harlow, E. S. (1959). Determination of particular matter in concentrated aerosols: Application to "tar" and nicotine in cigarette smoke. Journal of the Association of Official Analytical Chemists, 31, 1705-1709.

(Manuscript received January 4, 1984; revision accepted for publication March 9, 1984.) 